Research Article

\title{
Experimental Study on Cracking Behavior and Mechanism in Desiccating Soils in Xi'an, Shaanxi Province, China
}

\author{
Xin Wei $\mathbb{D}^{\text {, }}$, Chongyang Gao $(\mathbb{D}$, Dongdong Yan, and Ke Liu \\ Department of Civil Engineering, School of Human Settlements and Civil Engineering, Xi'an Jiaotong University, \\ Xi'an 710049, China \\ Correspondence should be addressed to Xin Wei; weixin_star@126.com
}

Received 25 September 2020; Revised 9 October 2020; Accepted 13 October 2020; Published 24 October 2020

Academic Editor: Chong Xu

Copyright $(92020$ Xin Wei et al. This is an open access article distributed under the Creative Commons Attribution License, which permits unrestricted use, distribution, and reproduction in any medium, provided the original work is properly cited.

Drying-induced cracks are frequently observed in soils, which can severely influence the mechanical parameters of soils in geotechnical engineering applications. In addition, geohazards can also be accelerated with the formation of preferential path in slopes caused by cracks in soils. This study aims to analyze the cracking behaviors and mechanisms of a special soil collected in northwestern China using experimental methods. Local displacements and strains can be obtained and analyzed with Digital Image Correlation (DIC) method. Combined with DIC method, the tensors maps with total "mechanical" principal strain are drawn. Cracks in mixed opening-sliding mode are identified and the curling phenomenon of soils is observed in situ. Three typical types of crack patterns are observed, which are "T," "Y," and "wave-ring," respectively. Crack pattern of "T" is more frequent than the other two types. The identification of cracking behaviors and mechanisms is helpful for the analysis of mechanical properties of soils and the prevention of geohazards in northwestern China.

\section{Introduction}

Cracks in soils are commonly observed in natural environments. The existence of cracks will change the mechanical parameters of soils such as strength, bearing capacity, permeability, compressibility, etc. Therefore, the hydromechanical properties of soils are greatly influenced by cracks [1-13]. Correspondently, the overall stability of Earth structures and soil foundations like slopes, buildings, and dams will be affected. The cracks on the surface of slopes will create preferential path for rainfall and runoff flows. Thus, the transport rate and velocity of water in soil profile will be greatly changed. In regions of soils with weak structures, the appearance of cracks will accelerate the weathering damage and erosion in soil slopes [14-17].

The process of cracking is complex. It is generally believed that soil cracks are mainly caused by the evaporation of water and uneven volume shrinkage under dry conditions [18]. The suction generated during the drying process of the soil will cause shrinkage. When the shrinkage deformation is limited, tensile stress will be generated inside the soil. Once the tensile stress exceeds the tensile strength of the soil, cracks will occur. Therefore, suction and tensile strength are considered to be the two key mechanical parameters that control the formation of cracks in soils [5, 19-21]. Péron et al. [22] found that, for homogeneous soils, boundary constraints and water gradients are important reasons for the generation of tensile stress and the formation of soil cracks. Tang et al. [21] believed that water content is an important factor affecting the generation of soil cracks. The factor that determines the degree of cracking is the gradient of water content inside the soil. The rate of soil dehumidification affects the gradient of water content, which is mainly related to hydraulic factors such as soil evaporation space. Therefore, the variation of water content is an important factor leading to soil cracking. The precipitation, air temperature, and humidity in the natural environment all influence water content of soils. Rainfall is a direct factor affecting the soil moisture. Air temperature and humidity can indirectly affect soil cracking by adjusting the evaporation rate of soil moisture [10]. The natural environmental temperature is an important external factor that affects the 
development of soil cracks, while the initial water content and dry density are important internal factors that influence the soil cracking.

In recent years, the phenomenon of soil cracking and the characteristics of cracks and their evolution mechanism have been hot issues. However, the researches on drying-induced cracks mainly focused on expansive soils, clays, and other soils. The crack morphology is paid much attention [23, 24]. Velde et al. [25] analyzed crack due to shrinkage in different types of arable soils in different countries by analyzing images of the cracking process. The geometric characteristics of the shrinkage crack surface were evaluated. Tang et al. [26] conducted laboratory experiments on observing cracks with expansive soils under different temperatures. The results verified that the parameters of cracks increase with increasing temperature. Horgan and Young [27] constructed a simulation model of soil shrinkage based on the two-dimensional fracture theory. Kodikara et al. [28] combined the results of Corte and Higashi [18] and Lau [29] to analyze the influence of soil layer on cracks through laboratory experiments. The influence of thickness, initial density of soil, cohesive force at the bottom of the container, and water evaporation rate on the geometry characteristics of dryinginduced cracks in clay were analyzed. Wei et al. [24, 30] observed the development of cracks in the surface of different mixtures of kaolin and montmorillonite during drying. The images were analyzed quantitatively and the relevant regulars of the cracking evolution on the surface of the soil were summarized. Tang et al. $[10-12,21]$ conducted a quantitative analysis of cracks in clays through laboratory experiments and the factors affecting the cracking patterns on the surface of soil samples were discussed. Although some achievements have been made in the domain of cracks morphology, there are still some questions that need to be further discussed, such as the dynamic evolution process and cracking mechanisms.

The objective of this research is to analyze the cracking behaviors and mechanisms of a special soil collected in northwestern China using experimental methods. The soils' samples used in this research are prepared as slurry with an initial water content equal to its limit liquidity. With Digital Image Correlation (DIC) method, the local displacements and strains can be obtained and analyzed. As a complementary approach, total "mechanical" principal strain is defined. With these two approaches, the cracking modes and different patterns of cracks can be clearly interpreted. The identification of cracking behaviors and mechanisms is helpful for the analysis of mechanical properties of soils and related engineering construction in northwestern China. Therefore, this research is significant for the prevention of geological hazards in northwestern China.

1.1. Study Area. The soil samples used in this study are collected in Xi'an, Shaanxi Province, China (see Figure 1). Shaanxi Province is in the northwest of China, where Chinese Loess Plateau locates. The soils here are called loess, a special soil for its sedimentary environment and material source. Because of the arid and semiarid climate in this region and material sources from $\mathrm{Mu}$ Us desert in northwestern China, loess is characterized for its red or yellow colour, loose structure, large pores, micro- or macrocracks, and original vertical joints. The area of Chinese Loess Plateau is about $440,000 \mathrm{~km}^{2}$. The physical properties of loess vary in different regions. The soils with small particle size and small density are prone to be transported with longer distance by wind. Thus, nearer the Mu Us desert, the grain size of soils is larger and their density is higher. Further away from the $\mathrm{Mu}$ Us desert, the soils are with finer particle size and small density.

$\mathrm{Xi}$ 'an is located nearly in the centre of Shaanxi province, where the particle size of soils is fine, and soils are classified as clayey loess. The climate in Xi'an is semihumid continental monsoon. The temperatures change dramatically in different seasons. The coldest average temperature is in January, about $-1.2^{\circ} \mathrm{C}-0.0^{\circ} \mathrm{C}$. The hottest average temperature is in July, about $-26.3^{\circ} \mathrm{C}-26.6^{\circ} \mathrm{C}$. The annual rainfall is nearly $522.4-719.5 \mathrm{~mm}$, increasing from north to south of Xi' an. Various meteorological disasters frequently happen in Xi'an, including drought, high temperature, sand and dust, and freezing damage. Thus, cracks related to desiccation are easily observed in fields or on the surface of land slopes (see Figure 2(a)). The cracks observed in situ are with different patterns, normally in "T," "Y," or "wave-ring" shapes. The cracks are hierarchical with different width. In order to better simulate the desiccation process in laboratory, the disturbed loess samples used in this research were collected from the surface of slopes where crack networks were observed. The detailed location of sampling site is presented in Figure 2(a).

In the loess slopes, pores, different scales of cracks and vertical joints are developed which can become the dominant seepage paths. Under rainfall conditions, these paths turn to be the dominant path for concentrated infiltration of rainfalls or runoff flow, which has a potential erosion effect on the loess slope. There are possibilities that the cracks connect with the internal flaws beneath the slope surface. During the suffosion process, the overwet contact point of water and soil first shrinks and collapses, and then more and more soil shrinks and collapses. Then the ability of loess to resist shear failure also decreases, causing the loess to collapse and disintegrate. Therefore, it can be considered that the contact between the infiltration of water and the loess according to the preferential path is an important way for the initiation and development of the subground erosions. The slope collapses, and over time, a hole in the loess is formed. The slopes beneath the erosion points are thus unstable (see Figure 3). Various geohazards can be caused by the appearance of cracks, for example, the subground erosions $[15,31]$, which is observed in situ in Xi'an, Shaanxi province (see Figure 2(d)).

\section{Materials and Methods}

2.1. Materials. Result of grain size distributions was determined by conventional sieving and sedimentation method. For the natural loess, the content of silt and clay content is $75 \%$ and $23 \%$, respectively (see Figure 4 ). The specific gravity 


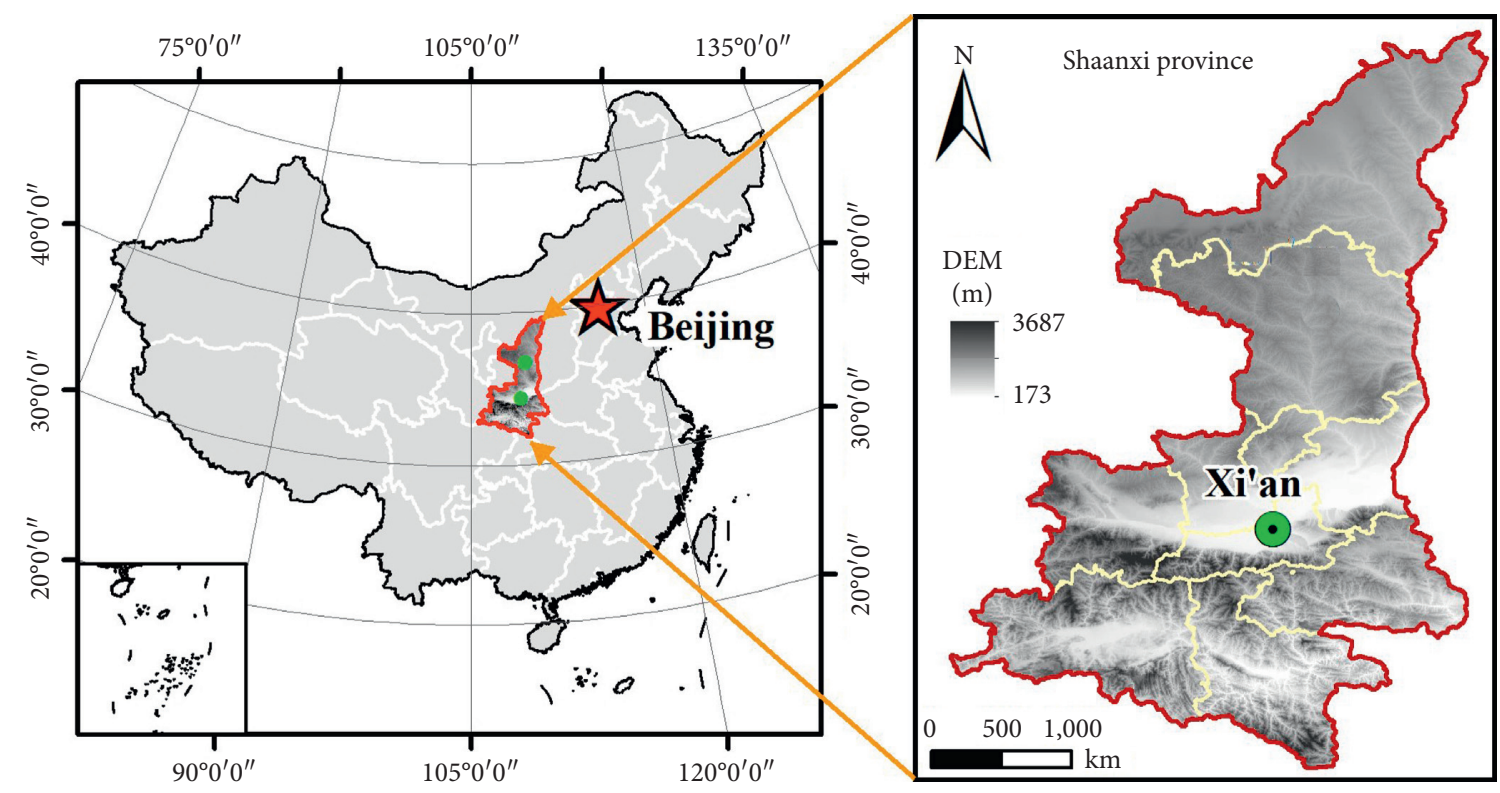

FIgURE 1: Study area of Xi'an, Shaanxi province, China.
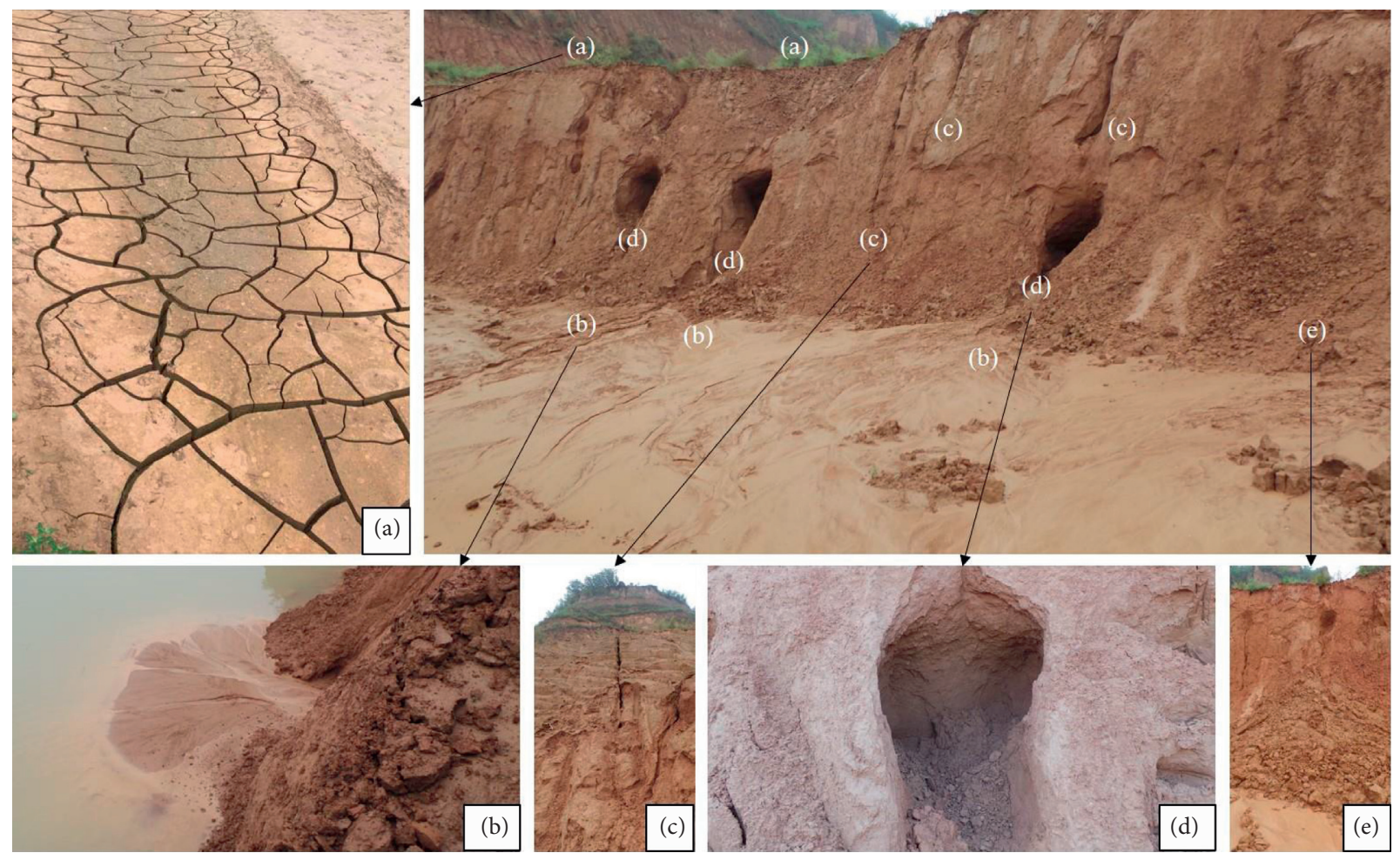

Figure 2: Field and in situ observations in Xi'an, Shaanxi province. (a) Cracks observed on the platform of slopes; (b) alluvial fan at the foot of subground erosion; (c) preferential path in slopes; (d) subground erosion in slopes; and (e) collapse of soils beneath the erosion point.

of natural soil is 2.69. Its liquid limit and plastic limit are $36 \%$ and $17 \%$, respectively. With X-ray diffraction method, the mineralogical analysis of the tested loess is performed. The main non-clay minerals are quartz and albite calcite. The predominant clay minerals in the study are montmorillonite, illite, kaolinite, and chlorite; the content percentage of which is $4.4 \%, 15.5 \%, 3.2 \%$, and $6.1 \%$, respectively. Microstructure of the natural loess is obtained by scanning electron microscopy (SEM) images (see Figure 5). The aggregate structures can be observed in the intact natural soil. Among 


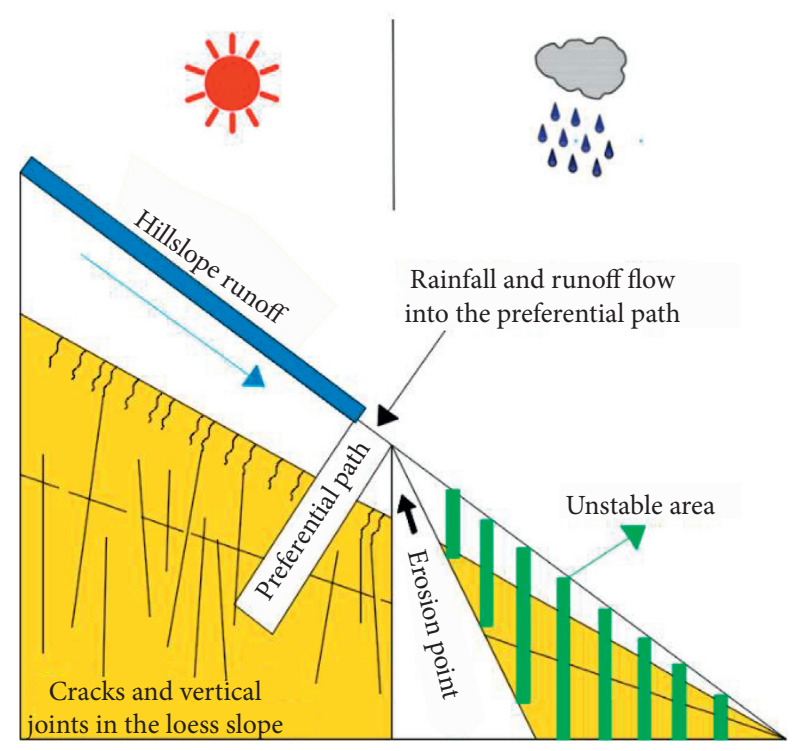

Figure 3: Diagram of rainfall and runoff flow into the preferential path created by cracks on the surface of slope.

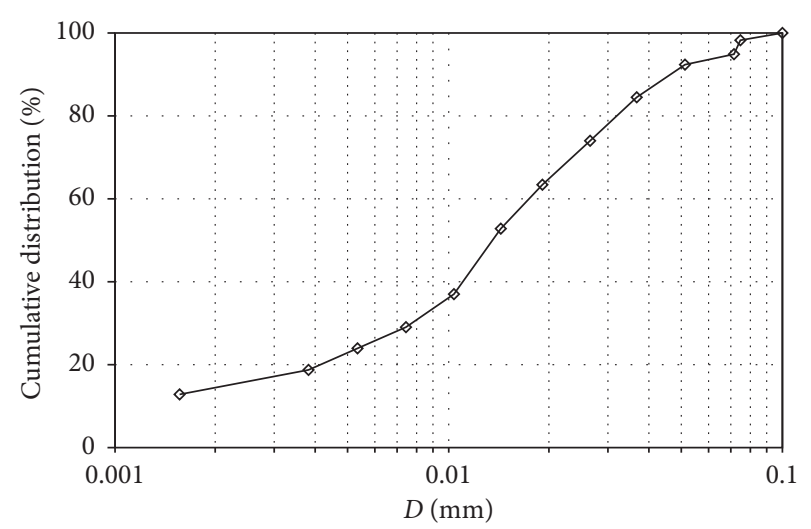

FIgURE 4: Grain size distribution of soils in Xi'an.

the aggregated particles and clayey particles, large voids exist. The natural soil is classified as clay of low plasticity (CL) according to the Unified Soil Classification System.

2.2. Experimental Methods. To better observe the cracking process of soils related to desiccation, an experimental system was set up in this study (see Figure 6). The tests were carried out in the laboratory under a constant temperature of $25^{\circ} \mathrm{C}$ and a relative humidity equal to $30 \pm 5 \%$. The soil sample in a slurry state was spread on a circle mold made of quartz, the diameter of which is $200 \mathrm{~mm}$. The thickness of the soil sample is $10 \mathrm{~mm}$. The support of the mold is nonwettable to water. The friction between the samples and the base materials is nearly zero. The initial water content of the soil sample is equal to its limit liquidity (36\%). Before the slurries were put into the circle mold, they had been mixed dramatically and sealed for about $24 \mathrm{~h}$ in order to reach a homogeneous state. The soil sample and the mold were weighed by a balance connected to a computer in order to measure the variations of water content of samples.

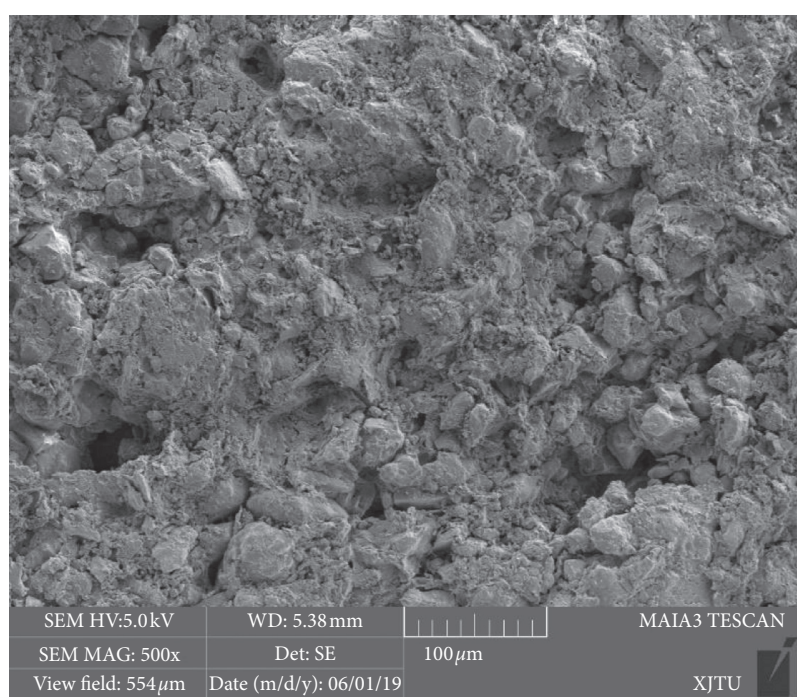

Figure 5: SEM observation of intact soils in Xi'an.

A camera was set up right above the soil sample for the purpose of capturing the successive images of the specimen during drying. The interval time of capturing the images is 10 minutes. Digital Image Correlation (DIC) method was combined with the desiccation tests. Before the soil deformed during drying, black paints were spread on the surface of soil samples in order to fabricate random-distributed speckles. With a commercial software Vic-2D, local displacements and strains were calculated with the reference image and deformed images by identifying and comparing the precise positions of these speckles. Two component displacements and three component strains can be obtained with Vic-2D, which are transversal displacement $U$ (along $x$ axis), longitudinal displacement $V$ (along $y$-axis), transversal strain $\varepsilon_{x x}$, longitudinal strain $\varepsilon_{y y}$, and shear strain $\varepsilon_{x y}$. An example of DIC results calculated by Vic-2D is presented in Figure 7 at $t=19.2 \mathrm{~h}$. The white vectors present the directions of displacements. The values of displacements are proportional to the length of vectors. Different colours, for example, red and violet, present different values of displacements and strains (see Figure 7).

\section{Results}

With DIC method, cracking behaviors and mechanisms are identified, including cracking modes, cracking development, and different cracking patterns.

3.1. Cracking Modes. Three modes of crack propagation have been identified in the framework of fracture mechanics: opening mode, sliding mode, and tearing mode. In this study, only cracks of the first two modes could be observed because the analysis of the desiccation tests was carried out in two dimensions. However, cracks in tearing mode can also be observed in situ. In order to better interpret the cracking mechanisms of soils, the total principal "mechanical" strains are defined in this study. It is assumed to be the difference between the total strains measured by Vic-2D 


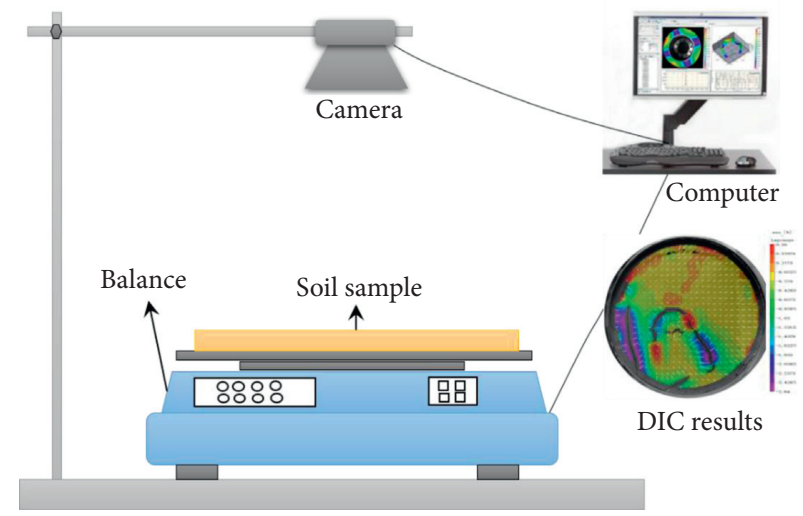

Figure 6: Diagram of experimental setup with Digital Image Correlation (DIC) methods.

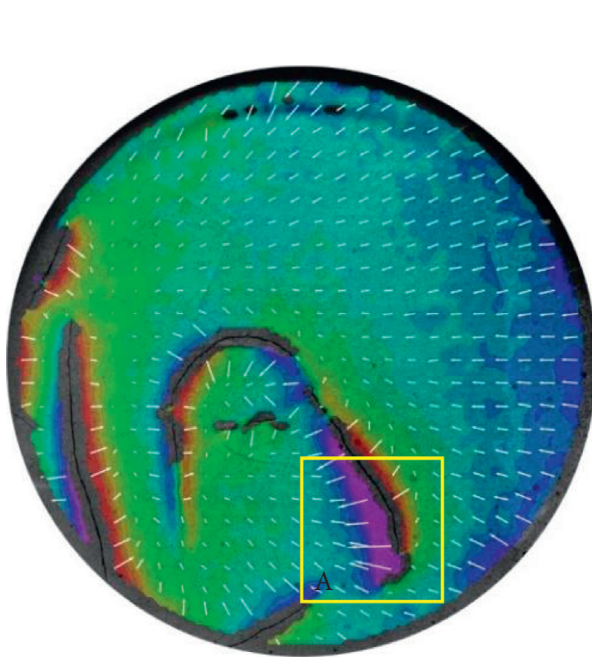

(a)

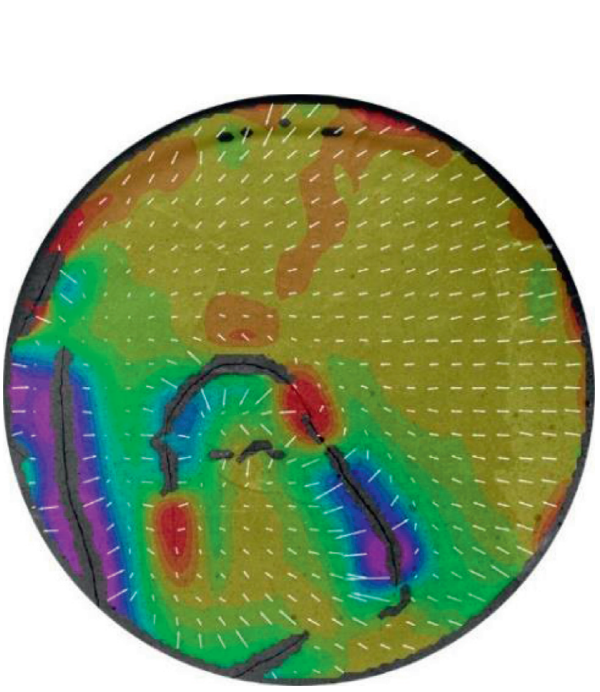

(c)

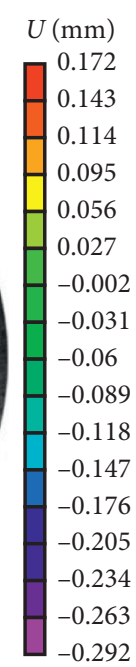

$e_{x x}(\%)$ Lagrange

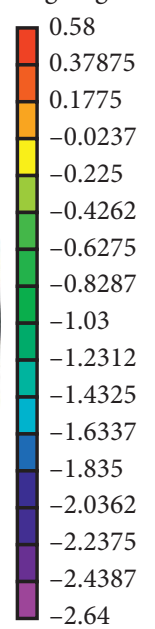

$-2.64$

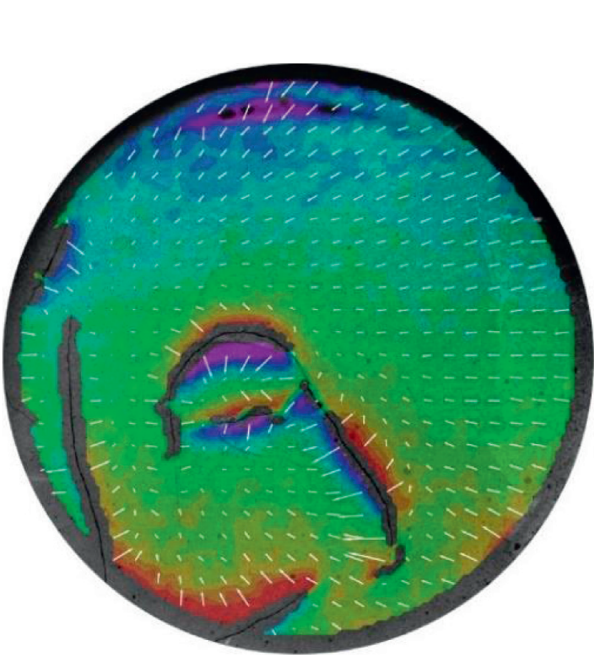

(b)

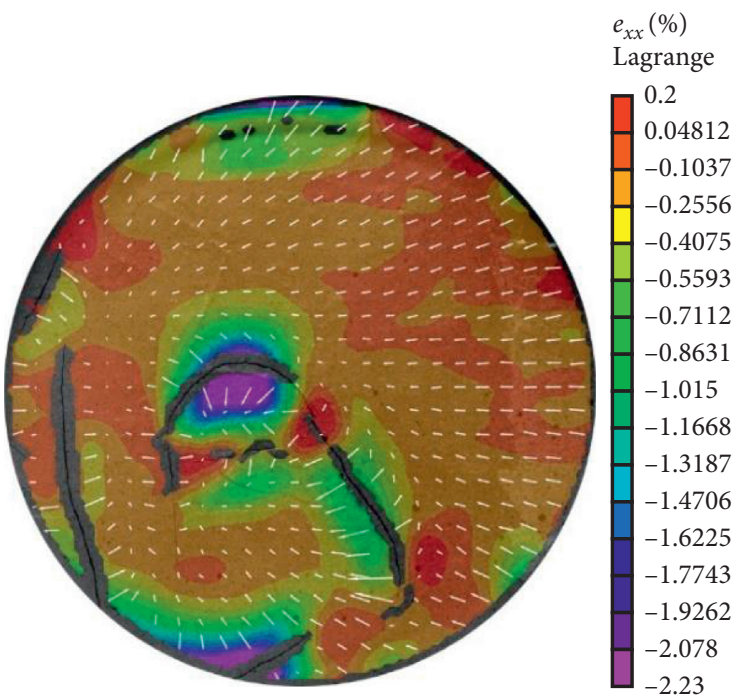

(d)

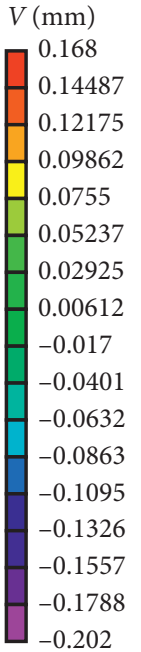

$-0.202$

$e_{x x}(\%)$

0.2
0.04812
-0.1037
-0.2556
-0.4075
-0.5593
-0.7112
-0.8631
-1.015
-1.1668
-1.3187
-1.4706
-1.6225
-1.7743
-1.9262
-2.078
-2.23

Figure 7: Continued. 


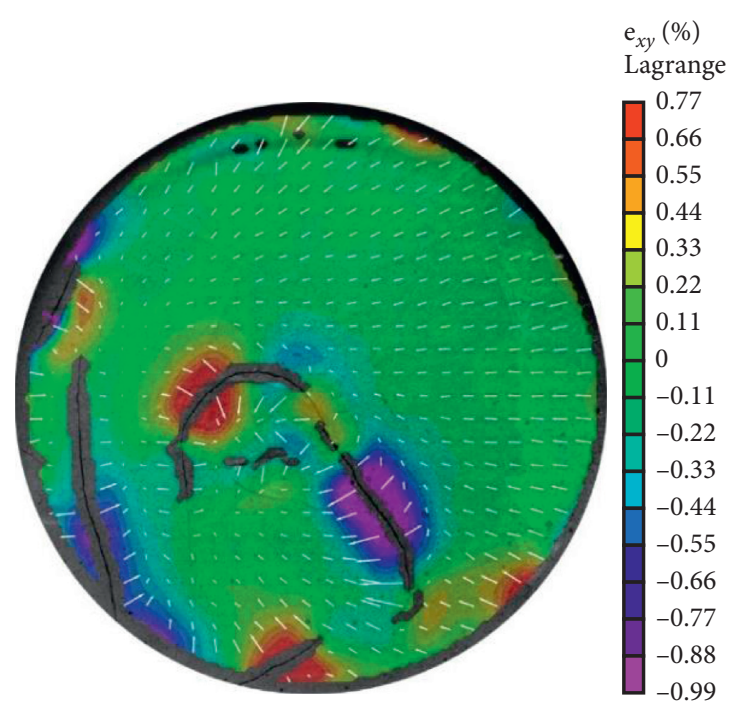

(e)

FIGURE 7: An example of DIC results of soils calculated by Vic-2D at $t=19.2 \mathrm{~h}$. (a) Longitudinal displacement $U$; (b) transversal displacement $V$; (c) longitudinal strain $\varepsilon_{x x} ;$ (d) transversal strain $\varepsilon_{y y}$; and (e) shear strain $\varepsilon_{x y}$.

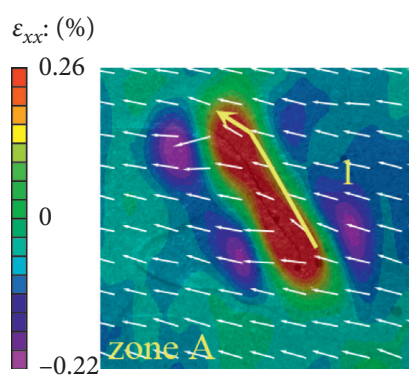

(a)

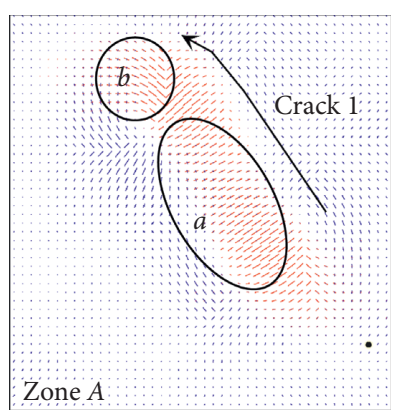

(b)

FIGURE 8: Cracks in mixed opening-sliding mode $t=16 \mathrm{~h}$. (a) Contour map of strains $\varepsilon_{x x}$; (b) schema of total principal "mechanical" strains in zone $A$.

and the shrinkage strains deduced by soil-water characteristics curves (SWCC) results [30]. An example of total principal "mechanical" strains is shown in Figure 8(b), where red vectors present extensions and blue vectors mean compressions.

3.2. Cracks in Mixed Opening-Sliding Mode. Cracks in opening mode are observed in the zone $A$ chosen from the image of DIC results in Figure 7 . At $t=16 \mathrm{~h}$, strains $\varepsilon_{x x}$ are between $0.26 \%$ and $-0.22 \%$. In the central vicinity (position a) of crack 1 in zone $A$, extensions are observed (see Figure $8(\mathrm{a})$ ). On the right side of crack 1, the directions of displacements are towards the west, whereas on the opposite side of crack 1, they are slightly towards the northwest, resulting in a crack opening nearly northwest. Figure 8 (b) shows the principal "mechanical" strains in zone $A$. It is evident that in the central part of crack 1, the direction is perpendicular to that of the principal extensions, which is the direction of the red vectors. The central part of crack 1 in zone $A$ can be identified to be caused by traction and corresponds eventually to an opening mode.

Cracks in sliding modes were also noticed in the same zone $A$ during propagation (see Figure $8(b)$ ). In the principal "mechanical" strains map, at the tip of crack 1 (position $b$ ), the strains parallel to the cracks are shown in red, which verifies the distribution of extensions. At the tip of crack 1, at the left side of crack 1, the direction of displacements is toward southwest, whereas on the right side of the crack, the direction is northwest. Total displacement consists of two components, one parallel to the direction of the crack and the other one perpendicular to the crack. The former component corresponds to a sliding mechanism, considering the difference between the displacements parallel to the direction of cracks on both sides. The latter component signifies the activation of an opening mechanism. As shown in Figure 8(b), the extensions are parallel to the direction of tip of crack 1.

Generally, the components of displacement vectors indicate that this crack is in mixed opening-sliding mode. It is 


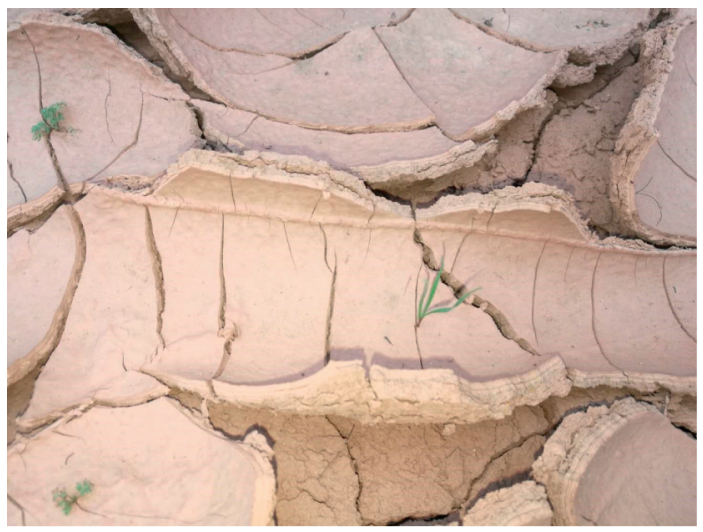

FIGURE 9: Curling of cracks observed in situ (Xi'an, Shaanxi province).

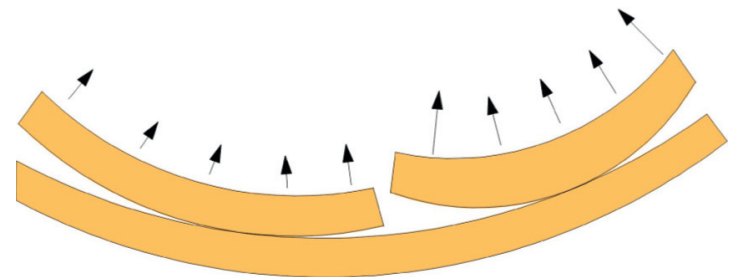

FIGURE 10: Diagram of curling phenomenon and crack in tearing mode.

noted that either alone or in combination with the sliding mode, the opening mode is always present.

3.3. Cracks in Tearing Mode. The desiccation tests were carried out in two dimensions without the observation of deformation in vertical direction. Therefore, the cracks in tearing mode cannot be observed in laboratory test. However, during the field investigations in Xi'an, many dryinginduced cracks in tearing mode were found in situ (see Figure 9). The different vertical displacements of cracks can be seen by naked eye. The surface of soils is not absolutely flat. The vertical displacement at the boundaries of cracks is larger than that in the centre of soil blocks. Between different soil blocks, the vertical displacement is not the same. Generally, this phenomenon can be called "curling" of cracks. The schematic diagram of curling phenomenon is presented in Figure 10. Cracks between two blocks can be considered to be in tearing mode because of the different vertical displacements in the two sides.

3.4. Evolution of Cracks. The evolution of cracks is observed and analyzed with successive photos of drying-induced cracks (see Figure 11). The first crack appears in the centre of the soil sample and propagates towards northwest $(t=15.3 \mathrm{~h})$. As interpreted in Figure 8, the initiation of crack 1 is caused by tension. In zone $a$ of the total principal "mechanical" strain map, it is the extension which causes the initiation and first-stage propagation of crack 1 (see Figure 8 ). With the development of time, crack 1 gradually changes its direction towards west $(t=16.3 \mathrm{~h})$. Finally, it propagates towards south and forms a wave-ring circle $(t=18.8 \mathrm{~h})$. The change of direction of crack 1 can be explained by the variation of strain fields in the vicinities of crack 1.

In zone $c$, at the propagation tip of crack $1(t=16.67 \mathrm{~h})$, the direction of extensions is parallel with the propagation directions of crack 1. As illustrated in Section 4, at the tip of crack 1, it is mainly the shear strains which accelerate the variation of crack direction (see Figure 12). When $t=19.2 \mathrm{~h}$, the direction of crack 1 has been changed to straight south. In the vicinities of crack 1 , the shear strains remain large (see Figure $7(\mathrm{e})$ ). Afterwards, more and more cracks appear with different length and shape. Some cracks connect together, forming a crack network. The soil samples are divided into separated soil blocks.

In order to better analyze the evolutions of displacements and strains, section 1 which cross through two points $A$ and $B$ of crack 1 was chosen (see Figure $11, t=19.5 \mathrm{~h}$ ). The local displacements and strains along section 1 with variations of time were analyzed. The longitudinal and transversal displacements versus different times are presented in Figures 13(a) and 13(b). It can be seen that in the beginning of desiccation, both the transversal and longitudinal displacements are relatively small. The average $U$ is less than $0.5 \mathrm{~mm}$ and the average $V$ is less than $0.2 \mathrm{~mm}$. With the development of time, both displacements increase in absolute values. When $t=17.8 \mathrm{~h}$, the $U$ decreases a little, which signifies the close possibility of crack 1 . However, at the two sides of point $A$ and point $B$ on crack 1 , the differences of displacements are very large, which verifies the evolutions of crack at these two points. The evolutions of longitudinal, transversal, and shear strains versus time are shown in Figures 13(c)-13(e), respectively. It is evident that the strains 


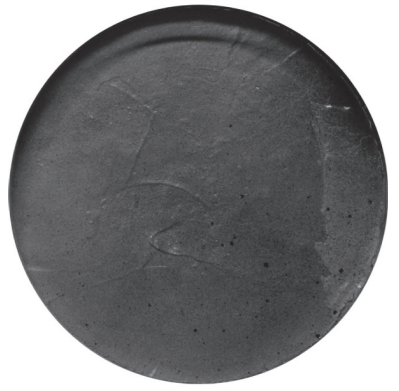

(a)

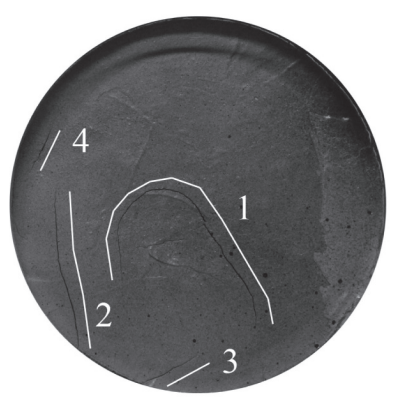

(e)

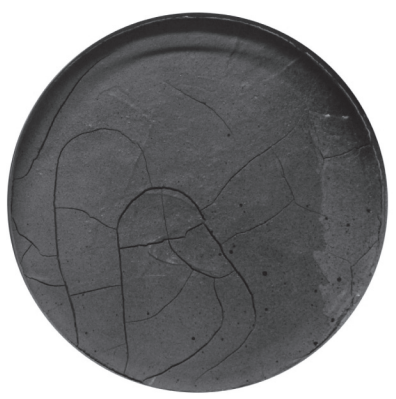

(i)

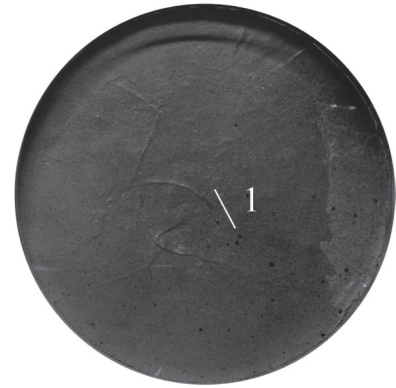

(b)

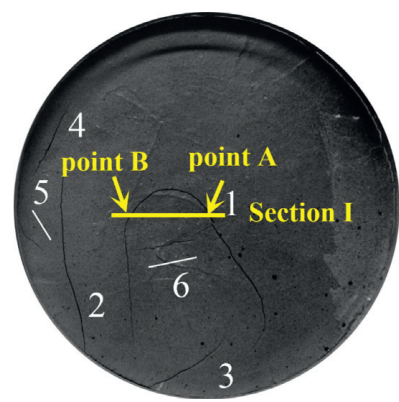

(f)

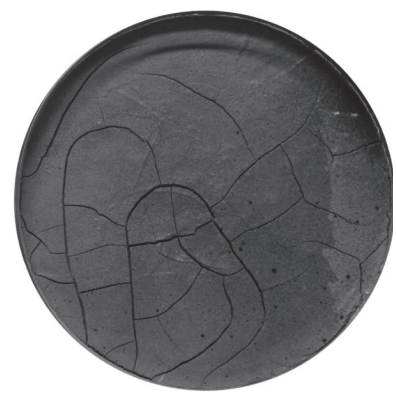

(j)

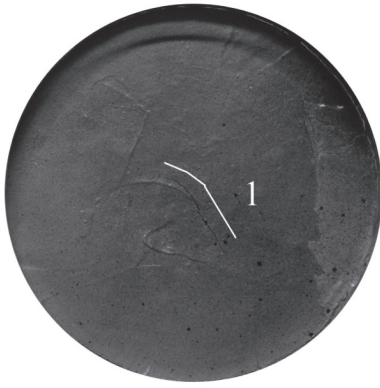

(c)

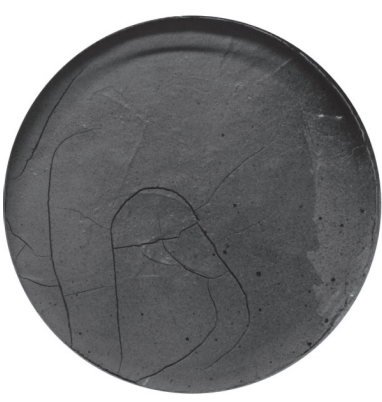

(g)

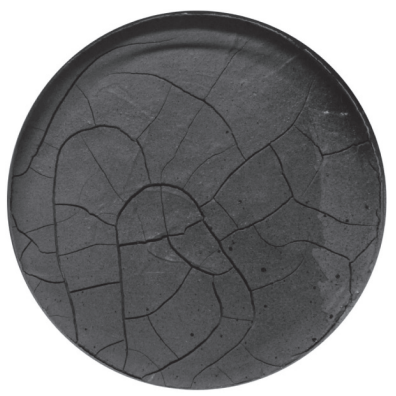

$(\mathrm{k})$

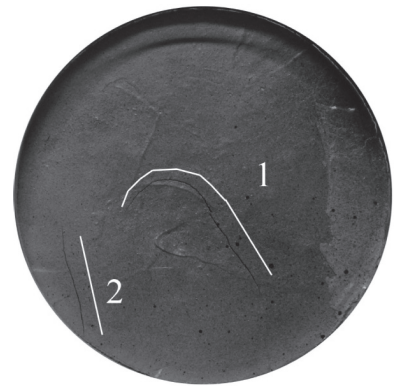

(d)

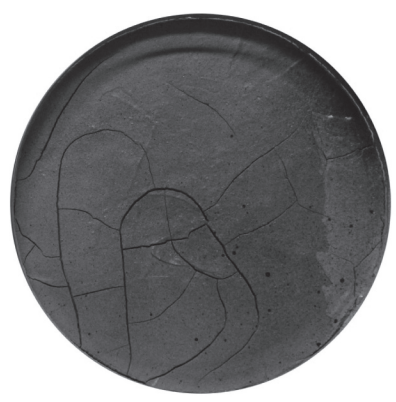

(h)

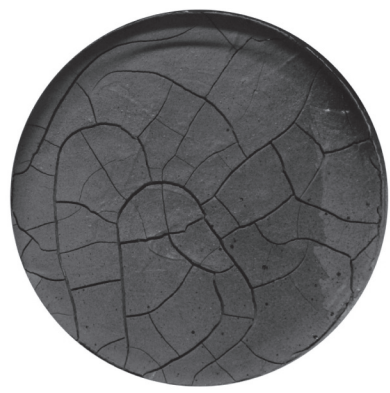

(l)

Figure 11: Evolution of cracks at different times. (a) $t=0 \mathrm{~h}$. (b) $t=15.3 \mathrm{~h}$. (c) $t=16.3 \mathrm{~h}$. (d) $t=17.8 \mathrm{~h}$. (e) $t=18.8 \mathrm{~h}$. (f) $t=19.5 \mathrm{~h}$. (g) $t=20.5 \mathrm{~h}$. (h) $t=21 \mathrm{~h}$. (i) $t=21.7 \mathrm{~h}$. (j) $t=22.5 \mathrm{~h}$. (k) $t=23.5 \mathrm{~h}$. (l) $t=24.8 \mathrm{~h}$.

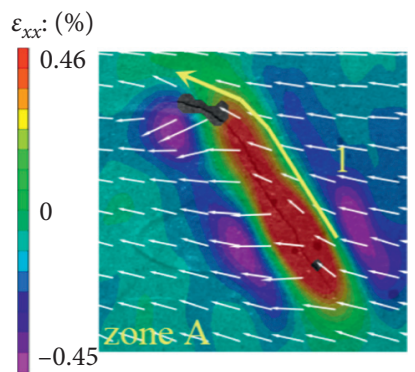

(a)

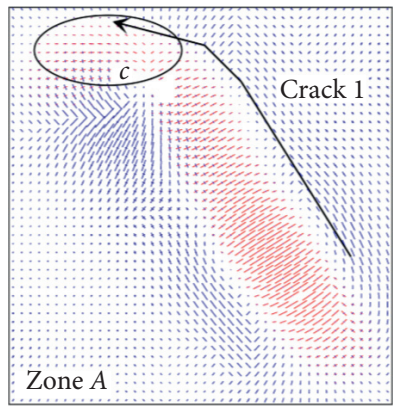

(b)

FIGURE 12: Cracks in mixed opening-sliding mode $t=16.67 \mathrm{~h}$. (a) Contour map of strains $\varepsilon_{x x}$; (b) schema of total principal "mechanical" strains in zone $A$.

are all very small in the beginning. Then they increase gradually. At the points $A$ and $B$ on crack 1 , strains are larger than the other positions. At point $A$, there are mainly extensions which cause the propagation of crack 1 . At the same time, strains decrease and change to compression in the vicinities of this point (see Figures 13(c) and 13(d)). At these two points on crack 1 , the shear strains are very large (see Figure 13(e)). The variation of displacements and strains 


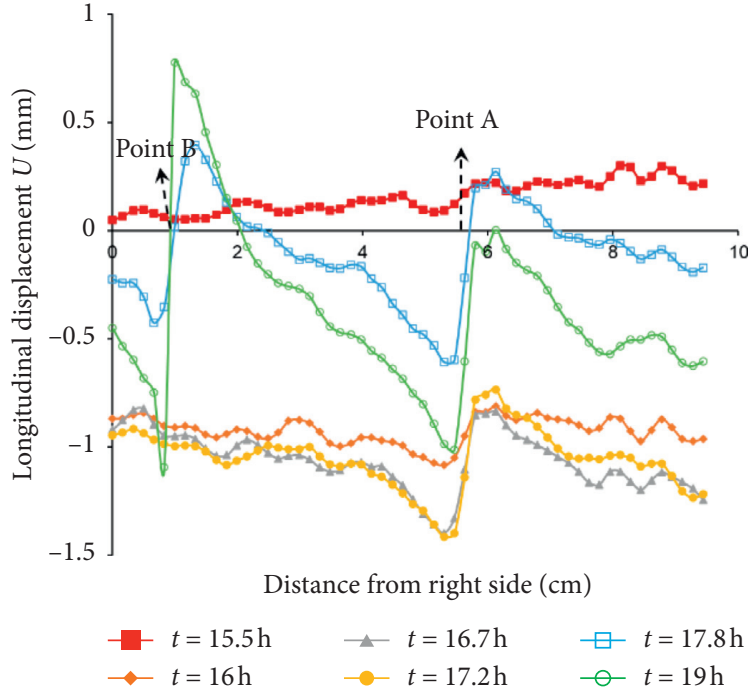

(a)

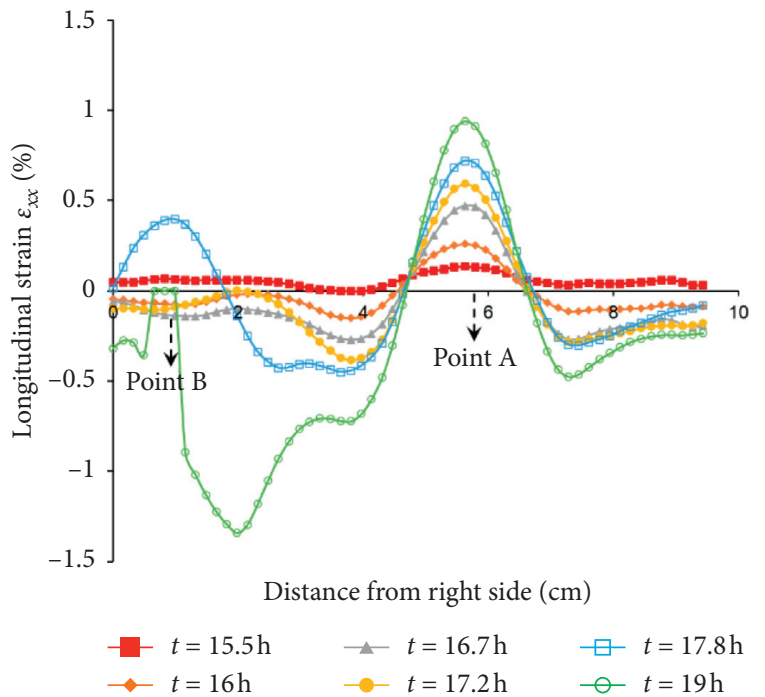

(c)

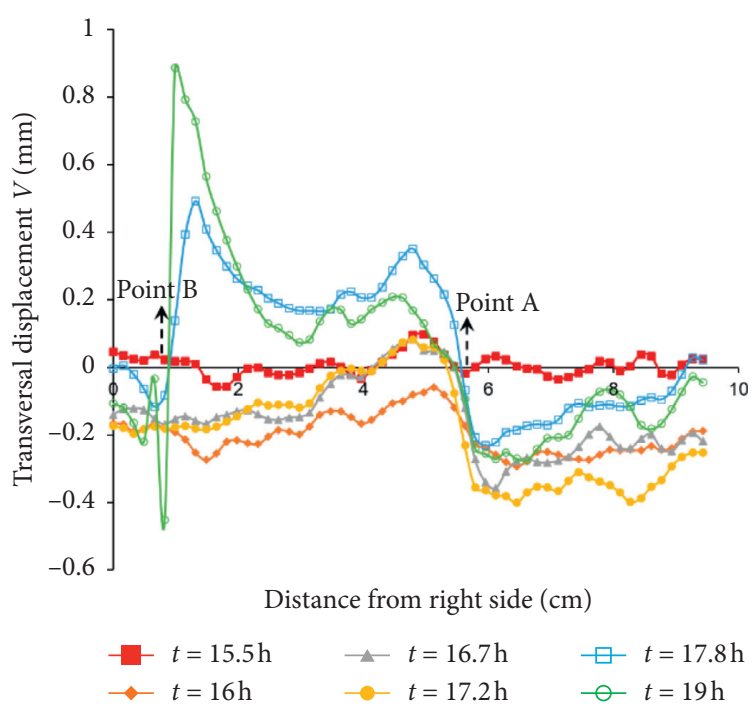

(b)

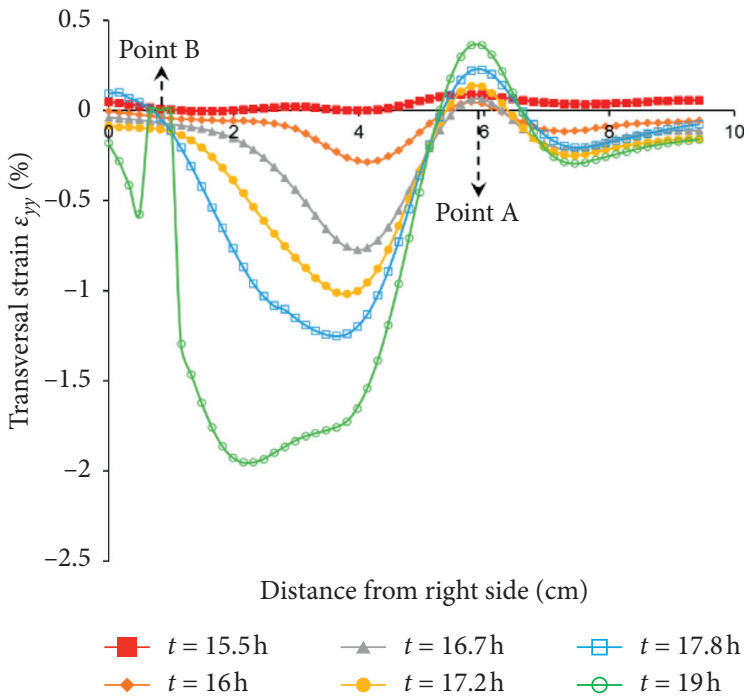

(d)

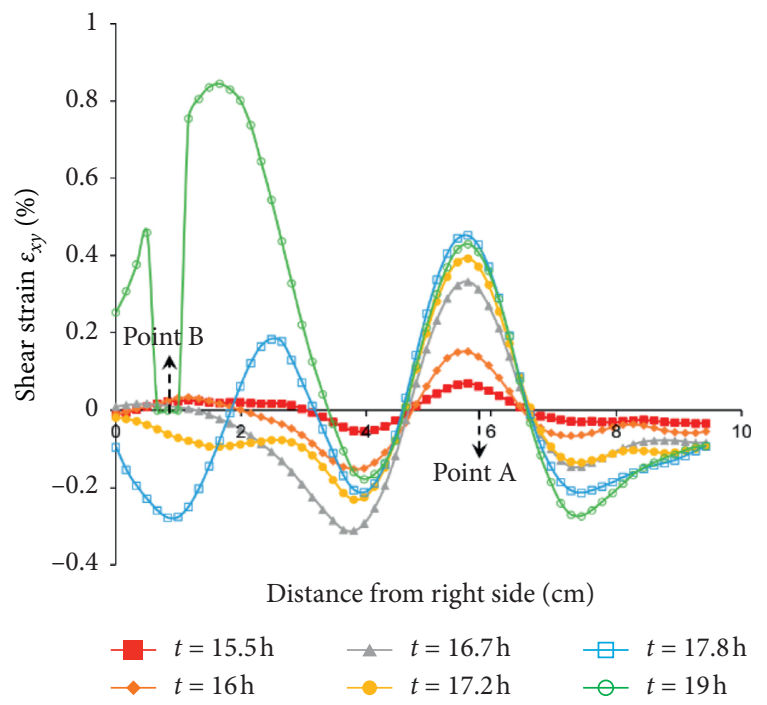

(e)

FIGURE 13: Evolution of $U, V, \varepsilon_{x x}, \varepsilon_{y y}$, and $\varepsilon_{x y}$ along section 1. (a) Longitudinal displacement $U$; (b) transversal displacement $V$; (c) longitudinal strain $\varepsilon_{x x}$; (d) transversal strain $\varepsilon_{y y}$; and (e) shear strain $\varepsilon_{x y}$. 


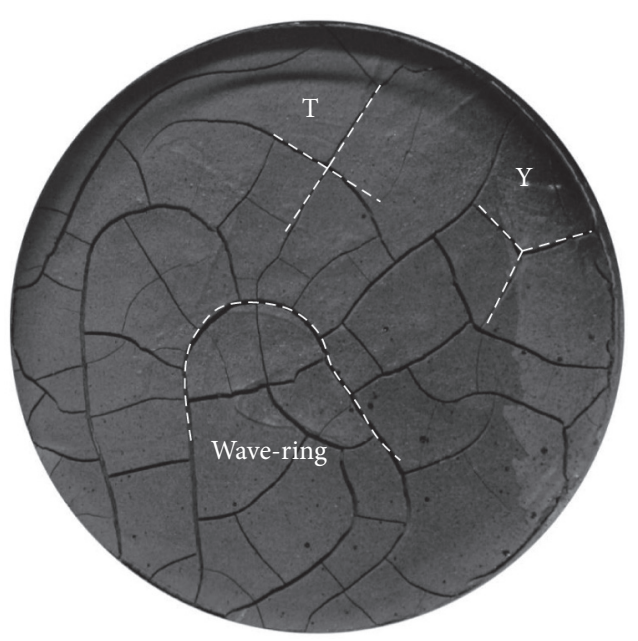

FIGURE 14: Different crack patterns observed in loess.

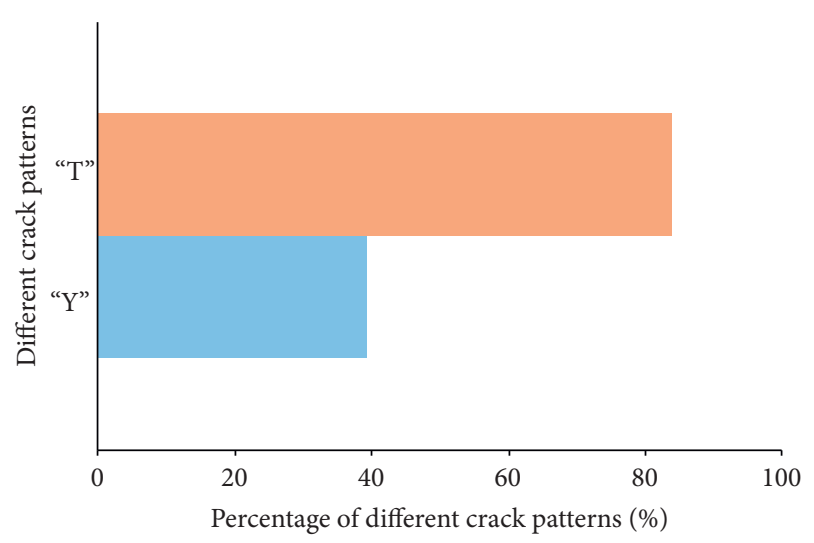

Figure 15: Percentages of different crack patterns.

versus different times is a significant method to illustrate the evolution of cracks.

3.5. Different Crack Patterns. The interactions of cracks at different angles can be observed in the crack networks. Similar to the cracks observed in situ, they can be classified as “T-," "Y-," and "wave-ring-" shaped crack patterns (see Figure 14). However, crack patterns of " $\mathrm{T}$ " are much more frequently formed than those of "Y." It is shown that the percentage of cracks which form " $\mathrm{T}$ "-shaped crack patterns is $83 \%$, whereas the number is about $39 \%$ for "Y-" shaped crack patterns. Some cracks form these two crack patterns at the same time so that the total percentage is larger than $100 \%$ (see Figure 15).

The cracks with the angle of $90^{\circ}$ are widely observed in the desiccation test. This is due to the release of energy when a crack has formed. The tensile stress perpendicular to the direction of cracks is nearly zero. A newly developed crack approaching the existing crack tends to propagate in the directions perpendicular to the local maximum tensile stresses, which is parallel with the direction of the existing crack. Therefore, the crack patterns of " $\mathrm{T}$ " frequently form.
The crack patterns of "Y" are produced due to the minimization of energy process. The formation of crack networks is a process of energy release. Considering that the tensile stresses at a given point are equal in any direction, the soil sample is prone to rupture along three planes because this will produce the smallest crack area with the maximum soil volume. As stated in the previous section, "wave-ring" crack is caused by the appearance of shear strains at the changing point.

\section{Conclusions}

In this research, desiccation tests were performed with a clayey loess in circle shape. The evolution mechanisms of cracks were interpreted with Digital Image Correlation (DIC) method and geometrical analysis. These are some main conclusions:

(1) Different cracking modes are detected in laboratory tests and in situ, respectively. The cracks in mixed opening-sliding mode are highlighted by DIC methods. As a complementary approach, the total "mechanical" principal strain is defined to be the differences between the total strains measured by Vic-2D software and the shrinkage strains deduced from SWCC results. For cracks in opening mode, the direction of extension is perpendicular to the propagating direction of cracks. While for cracks in sliding mode, the direction of extensions is parallel with the direction of cracks. Curling phenomenon can be observed in situ with the different vertical displacement at the two sides of crack, which is considered to be in tearing mode. It is noted that the opening mode is always along with the other two modes.

(2) The evolution of cracks is observed and analyzed with successive photos of drying-induced cracks. The variations of local displacements and strains at different times are an efficient way to illustrate the evolution of cracks. At the two sides of a crack, the displacements vary dramatically, which signifies the existence of extension. In the position where cracks appear, the strains are larger than those at the other areas. During the propagation process of cracks, three crack patterns are identified as “T," "Y," and "wave-ring." Cracks patterns of " $\mathrm{T}$ " caused by the energy release in the vicinities of cracks are more frequent than the other two types. The crack patterns of "Y" are produced due to the minimization of energy process. "Wave-ring" crack is caused by the appearance of shear strains at the changing point.

(3) It is also noted that, different from expansive or other clayey soils, loess has a unique microstructure, which is composed of single mineral particles, aggregates, cementing materials, and micropores. The permeability, evaporation characteristics, and hydraulic properties of loess are closely related to this special structure. The cracking behaviors of loess used in this study may be differed from other soils because of this 
complex microstructure. Concerning the cracking mechanisms and cracking modes, the behaviors of loess samples collected in Xi'an were found to be quite similar with those of other clays (e.g., $[12,13,30])$. However, because of the effect of mineralogy, thickness, boundary conditions, and initial water contents of the different tested materials, the kinetic of formation, and development of cracks is not the same. In addition, the final patterns of cracks are somewhat different in different soils. For example, the shapes of soil blocks divided by cracks in this study are more regular and the connections of cracks are smoother than those observed in the research of Wei et al. [30]. Thus, many soil parameters play a part in the formation of cracks: plasticity, grain size distribution, rheology, etc., resulting in different patterns for different soils.

(4) In the loess slopes, pores, different scales of cracks and vertical joints are developed which can become the dominant seepage paths. Under rainfall conditions, these paths turn to be the dominant path for concentrated infiltration of rainfalls or runoff flow, which has a potential erosion effect on the loess slope. There are possibilities that the cracks connect with the internal flaws beneath the slope surface. During the suffosion process, the overwet contact point of water and soil first shrinks and collapses, and then more and more soil shrinks and collapses. Due to the influence of seepage and the coalescence of cracks with other flaws, geohazards like subground erosions and landslides are prone to happen in loess areas.

\section{Data Availability}

The data used to support the findings of this study are included within the article.

\section{Conflicts of Interest}

The authors declare that there are no conflicts of interest regarding the publication of this paper.

\section{Acknowledgments}

This work was supported by the National Key Research and Development Program of China (no. 2018YFC1504700), Natural Science Foundation of China funded project (no. 41790441), and the China Postdoctoral Science Foundation (Project no. 2017M623180).

\section{References}

[1] S. Frydman, "Triaxial and tensile strength tests on stabilized soil," in Proceedings of the $3 r$ d Asian Regional Conference on Soil Mechanics and Foundation Engineering, vol. 1, pp. 269271, Haifa, Israel, 1967.

[2] T. T. Chen, J. E. Dutrizac, D. R. Owens et al., "Accelerated tarnishing of some chalcopyrite and tennantite specimens," Canadian Mineralogist, vol. 18, no. 2, pp. 173-180, 1980.
[3] I. Ravina, The Influence of Vegetation on Moisture and Volume Changes, The Institution of Civil Engineers, Thomas Telford Ltd., London, UK, 1984.

[4] G. Bagge, "Tension cracks in saturated clays cuttings," in Proceedings of the 11th International Conference on Soil Mechanics and Foundation Engineering, pp. 393-395, San Francisco, CA, USA, August 1985.

[5] P. H. Morris, J. Graham, and D. J. Williams, "Cracking in drying soils," Canadian Geotechnical Journal, vol. 29, no. 2, pp. 263-277, 1992.

[6] G. Avila, "Study of shrinkage and cracking of clays-application to clay in Bogota," Doctoral dissertation, Polytechnic University of Catalunya, Barcelona, Spain, 2004.

[7] S. Tahéri, "The high cycle thermal fatigue cracking, a problem bound to the structure," in Proceedings of the French Congress of Mechanics, vol. 29, Paris, France, August 2005.

[8] H. Péron, "Desiccation cracking of soils," Doctoral dissertation, Ecole Polytechnique Fédérale de Lausanne, Lausanne, Switzerland, 2008.

[9] T. Maison, "Analyse à l'échelle microscopique des phénomènes d'humectation et de dessiccation des argiles," Doctoral dissertation, Ecole Centrale, Paris, France, 2011.

[10] C. S. Tang, B. Shi, C. Liu et al., "Influencing factors of geometrical structure of surface shrinkage cracks in clayey soils," Engineering Geology, vol. 101, no. 3-4, pp. 204-217, 2008.

[11] C. S. Tang, B. Shi, C. Liu, W. B. Suo, and L. Gao, "Experimental characterization of shrinkage and desiccation cracking in thin clay layer," Applied Clay Science, vol. 52, no. 1-2, pp. 69-77, 2011.

[12] C. S. Tang, B. Shi, Y. J. Cui, C. Liu, and K. Gu, "Desiccation cracking behavior of polypropylene fiber-reinforced clayey soil," Canadian Geotechnical Journal, vol. 49, no. 9, pp. 1088-1101, 2012.

[13] L.-L. Wang, C.-S. Tang, B. Shi, Y. J. Cui, G.-Q. Zhang, and I. Hilary, "Nucleation and propagation mechanisms of soil desiccation cracks," Engineering Geology, vol. 238, pp. 27-35, 2018.

[14] H. Lu, J. Li, W. Wang, and C. Wang, "Cracking and water seepage of Xiashu loess used as landfill cover under wettingdrying cycles," Environmental Earth Sciences, vol. 74, no. 11, pp. 7441-7450, 2015.

[15] Q. Lu, J. Peng, Z. Chen, and X. Li, "Research on characteristics of cracks and fissures of loess and their distribution in loess plateau of China," Journal of Soil Water Conservation, vol. 19, no. 5, pp. 191-194, 2005.

[16] P. Sun, "Experimental research on rupture mechanisms of loess," Ph.D. thesis, Chang'an University, Xi'an, China, 2007.

[17] Y. Zhang, W. M. Ye, B. Chen, Y. G. Chen, and B. Ye, "Desiccation of NaCl-contaminated soil of earthen heritages in the site of Yar city, northwest China," Applied Clay Science, vol. 124-125, pp. 1-10, 2016.

[18] A. Corte and A. Higashi, Experimental Research on Desiccation Cracks in Soils, U.S. Army Snow Ice \& Permafrost Research Establishment, Hanover, NH, USA, 1964.

[19] J. K. Mitchell and K. Soga, Fundamentals of Soil Behaviour, John Wiley \& Sons, Hoboken, NY, USA, 3rd edition, 2005.

[20] N. Yesiller, C. J. Miller, G. Inci, and K. Yaldo, "Desiccation and cracking behavior of three compacted landfill liner soils," Engineering Geology, vol. 57, no. 1-2, pp. 105-121, 2000.

[21] C.-S. Tang, B. Shi, C. Liu, L. Gao, and H. I. Inyang, "Experimental investigation of the desiccation cracking behavior of soil layers during drying," Journal of Materials in Civil Engineering, vol. 23, no. 6, pp. 873-878, 2011. 
[22] H. Péron, T. Hueckel, L. Laloui, and L. B. Hu, "Fundamentals of desiccation cracking of fine-grained soils: experimental characterisation and mechanisms identification," Canadian Geotechnical Journal, vol. 46, no. 10, pp. 1177-1201, 2009.

[23] X. Peng, R. Horn, S. Peth, and A. Smucker, "Quantification of soil shrinkage in $2 \mathrm{D}$ by digital image processing of soil surface," Soil and Tillage Research, vol. 91, no. 1-2, pp. 173-180, 2006.

[24] X. Wei, "Etude micro-macro de la fissuration des argiles soumises à la desiccation," Doctoral dissertation, Ecole Centrale, Paris, France, 2014.

[25] B. Velde, "Structure of surface cracks in soil and muds," Geoderma, vol. 93, no. 1-2, pp. 101-124, 1999.

[26] C. S. Tang, Y. J. Cui, A. M. Tang et al., "Experiment evidence on the temperature dependence of desiccation cracking behavior of clayey soils," Engineering Geology, vol. 114, no. 3-4, pp. 261-266, 2010.

[27] G. W. Horgan and I. M. Young, "An empirical stochastic model for the geometry of two-dimensional crack growth in soil (with discussion)," Geoderma, vol. 96, no. 4, pp. 263-276, 2000.

[28] J. K. Kodikara, S. L. Barbour, and D. G. Fredlund, "Desiccation cracking of soil layers," in Proceedings of the Asian Conference in Unsaturated Soils, pp. 693-769, Singapore, May 2000.

[29] J. T. K. Lau, "Desiccation cracking of clay soils," Master thesis, University of Saskatchewan, Saskatoon, Canada, 1987.

[30] X. Wei, M. Hattab, P. Bompard, and J. M. Fleureau, "Highlighting some mechanisms of crack formation and propagation in clays on drying path," Géotechnique, vol. 66, no. 4, pp. 287-300, 2016.

[31] J. B. Peng, Disasters about Loess Caves, Science Press, Beijing, China, 2007. 